\title{
Is Maternal Progesterone Actually Independent of the Fetal Steroids?
}

\author{
M. HILL ${ }^{1}$, A. PAŘÍZEK ${ }^{2}$, J. E. JIRÁSEK ${ }^{3}$, M. JIRKOVSKÁ ${ }^{5}$, M. VELÍKOVÁ ${ }^{1}$, \\ M. DUŠKOVÁ ${ }^{1}$, M. KLÍMKOVÁ ${ }^{2}$, A. PAŠKOVÁ ${ }^{2}, Z$. ŽIŽKA ${ }^{2}$, A. GERMANOVÁ ${ }^{4}$, \\ M. KOUCKÝ ${ }^{2}$, M. KALOUSOVÁ ${ }^{4}$, L. STÁRKA ${ }^{1}$
}

${ }^{1}$ Institute of Endocrinology, Prague, Czech Republic, ${ }^{2}$ Department of Obstetrics and Gynecology of the First Faculty of Medicine and General Teaching Hospital, Prague, Czech Republic, ${ }^{3}$ Institute for the Care of Mother and Child, Prague, Czech Republic, ${ }^{4}$ Department of Clinical Chemistry and Laboratory Diagnostics of the First Faculty of Medicine and General Teaching Hospital, Prague, Czech Republic, ${ }^{5}$ Insitute for Histology and Embryology of the First Faculty of Medicine and General Teaching Hospital, Prague, Czech Republic

Received April 10, 2009

Accepted June 16, 2009

On-line June 19, 2009

\section{Summary}

Progesterone and estradiol are the foremost steroid hormones in human pregnancy. However, the origin of maternal progesterone has still not been satisfactorily explained, despite the generally accepted opinion that maternal LDL-cholesterol is a single substrate for placental synthesis of maternal progesterone. The question remains why the levels of progesterone are substantially higher in fetal as opposed to maternal blood. Hence, the role of the fetal zone of fetal adrenal (FZFA) in the synthesis of progesterone precursors was addressed. The FZFA may be directly regulated by placental $\mathrm{CRH}$ inducing an excessive production of sulfated $3 \beta$-hydroxy-5-ene steroids such as sulfates of dehydroepiandrosterone (DHEAS) and pregnenolone (PregS). Due to their excellent solubility in plasma these conjugates are easily transported in excessive amounts to the placenta for further conversion to the sex hormones. While the significance of C19 33-hydroxy-5-ene steroid sulfates originating in FZFA for placental estrogen formation is mostly recognized, the question "Which maternal and/or fetal functions may be served by excessive production of PregS in the FZFA?" - still remains open. Our hypothesis is that, besides the necessity to synthesize de novo all the maternal progesterone from cholesterol, it may be more convenient to utilize the fetal PregS. The activities of

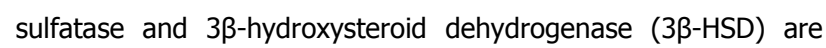
substantially higher than the activity of cytochrome P450scc, which is rate-limiting for the placental progesterone synthesis from LDL-cholesterol. However, as in the case of progesterone synthesis from maternal LDL-cholesterol, the relative independence of progesterone levels on FZFA activity may be a consequence of substrate saturation of enzymes converting PregS to progesterone. Some of the literature along with our current data (showing no correlation between fetal and maternal progesterone but significant partial correlations between fetal and maternal 20a-dihydroprogesterone (Prog20a) and between Prog20a and progesterone within the maternal blood) indicate that the localization of individual types of $17 \beta$-hydroxysteroid dehydrogenase is responsible for a higher proportion of estrone and progesterone in the fetus, but also a higher proportion of estradiol and Prog20a in maternal blood. Type 2 $17 \beta$-hydroxysteroid dehydrogenase (17HSD2), which oxidizes estradiol to estrone and Prog20a to progesterone, is highly expressed in placental endothelial cells lining the fetal compartment. Alternatively, syncytium, which is directly in contact with maternal blood, produces high amounts of estradiol and Prog20a due to the effects of type 1,5 and 7 17ß-hydroxysteroid dehydrogenases (17HSD1, 17HSD5, and 17HSD7, respectively). The proposed mechanisms may serve the following functions: 1) providing substances which may influence the placental production of progesterone and synthesis of neuroprotective steroids in the fetus; and 2) creating hormonal milieu enabling control of the onset of labor.

\section{Key words}

Steroids - Progesterone - 20a-dihydroprogesterone • Labor • Plasma $\bullet$ Metabolome $\bullet$ GC-MS

\section{Corresponding author}

M. Hill, Institute of Endocrinology, Národní trída 8, Prague, CZ 116 94, Czech Republic. Fax: +420-2-24905 325. E-mail: mhill@endo.cz 


\section{Introduction}

The role of progesterone in the sustaining of human pregnancy is widely known. But the origin of progesterone in the maternal compartment has still not been satisfactorily explained, despite the generally accepted opinion that progesterone is synthesized in the placenta independently of fetal steroids from the cholesterol which is transported from the maternal compartment (Carr and Simpson 1982, Runnebaum and Rabe 1983, Hercz et al. 1988, Braunstein 2003). Although this principle conforms with the absence of correlation between maternal and fetal progesterone, there remains a question to be answered: "Why are the levels of progesterone and $5 \alpha$-dihydroprogesterone (P5 $\alpha$ ) in the fetal serum substantially higher when compared to the maternal circulation ?" (Runnebaum et al. 1975, Antonipillai and Murphy 1977, Mathur et al. 1980, Farquharson and Klopper 1984, Hercz et al. 1988, Kawamura et al. 1989, Lofgren and Backstrom 1997) Hence the role of the fetal zone of fetal adrenal (FZFA) in the synthesis of progesterone precursors was addressed (Donaldson et al. 1991).

FZFA cells lacking 3ß-hydroxysteroid dehydrogenase (3ß-HSD) may be directly regulated by placental corticotropin-releasing hormone (CRH) (Smith et al. 1998, Smith 2007). Several studies have shown an association between the levels of maternal plasma CRH of placental origin and the timing of parturition (Warren et al. 1992, Hobel et al. 1999, Ellis et al. 2002). CRH is secreted from the placenta predominantly into the maternal blood, but it also enters fetal circulation (Goland et al. 1993). The maternal plasma CRH levels increase exponentially as pregnancy advances, peaking at the time of delivery. In women who deliver preterm the exponential increase is rapid, whereas in women who deliver after the estimated date of delivery the rise is slower (McLean et al. 1995, Nodwell et al. 1999, Torricelli et al. 2006). These data indicate that CRH stimulation may induce an excessive production of several sulfated 3 3 -hydroxy-5-ene steroids, including dehydroepiandrosterone sulfate (DHEAS) and pregnenolone sulfate (PregS). While the levels of DHEAS in fetal blood do not exceed the levels of DHEAS in non-pregnant women (Mathur et al. 1980, Sulcova et al. 1997), the levels of PregS in fetal blood exceed by about 30 times the PregS concentrations in women who are not pregnant (Laatikainen et al. 1980, Mathur et al. 1980, Havlíková et al. 2002).
Production of CRH by the placenta is specific for primates, but only big apes show an exponential rise similar to that in humans. Glucocorticoids stimulate expression of the $\mathrm{CRH}$ gene and production of $\mathrm{CRH}$ by the placenta. In turn, CRH stimulates the pituitary to produce $\mathrm{ACTH}$, provoking cortisol synthesis in the adrenal cortex. A positive feed-forward loop is formed. The fetal zone of the adrenal glands rapidly involutes after delivery of the placenta, indicating that placental factors, such as $\mathrm{CRH}$, maintain the fetal zone (Smith 2007).

Due to their high polarity, the sulfated $3 \beta$ hydroxy-5-ene steroids, like PregS and DHEAS, are excellently soluble in the plasma and may be easily transported in excessive amounts from the FZFA to placenta for further conversion to sex hormones. The levels of PregS in the blood from umbilical artery are about a hundred times higher than those of unconjugated pregnenolone. Pregnenolone is lipophilic and therefore hardly soluble in plasma. The difference between DHEAS and DHEA levels is even more prominent (Mathur et al. 1980).

As reported by Komatsuzaki et al. (1987), PregS circulating in maternal blood can be a precursor of various $\mathrm{C} 21$ steroids, but due to the absence of cytochrome P45017 $\alpha$ in the placenta (Pepe and Albrecht 1995, Miller 1998) it cannot be the precursor of C19 and C18 steroids. In all probability a similar situation may be expected in the fetus. Obviously, there is a little possibility that fetal PregS may be converted to placental estrogens. The significance of C19 3ß-hydroxy-5-ene steroid sulfates, originating in FZFA, for placental estrogen formation determining estrogen levels in both the fetal and maternal compartments is widely recognized (Smith et al. 1998, Nodwell et al. 1999, Smith 2007), albeit some former reports indicated the source of estrogen synthesis in the maternal compartment (Keresztes et al. 1988). Nevertheless, the question of what the excessive production of PregS in the FZFA is good for still remains.

\section{The hypothesis}

As in a number of physiological processes, in the case of placental progesterone synthesis there may be at least two fungible ways leading to the same goal. Besides the utilization of maternal cholesterol there might be another source for progesterone synthesis depending on the fetal adrenal steroidogenesis and consuming the 
precursor, which is freely available in fetal, but not in maternal circulation. Instead of synthesizing de novo all maternal progesterone from cholesterol, it would be biologically more efficient to utilize PregS amply supplied by FZFA. Placenta freely expresses enzymes necessary for hydrolysis of PregS and conversion of pregnenolone to progesterone (Li et al. 2005, Selcer et al. 2007). The activity of $3 \beta-H S D$ in the placenta is substantially higher than that of cytochrome P450scc and is not rate-limiting for placental progesterone synthesis (Winkel et al. 1980, Boguslawski 1983, Tuckey 2005). The PregS levels are significantly lower in umbilical vein than those in UA. Alternatively, pregnenolone shows either no difference between sera from the umbilical artery (UA) and umbilical vein (UVn), or there is a decreasing gradient from UA to UVn of borderline significance (Laatikainen et al. 1980, Mathur et al. 1980, Kawamura et al. 1989). The former data probably reflect the ready desulfation of PregS in the placenta, while the latter data might indicate saturation of the $3 \beta-\mathrm{HSD}$ capacity by pregnenolone.

However, the considered possibility that maternal progesterone may be partly dependent on fetal steroidogenesis raises the question of how the absence of correlation between maternal and fetal progesterone levels (Oszczygiel 1975, Farquharson and Klopper 1984, Hercz et al. 1988) can be explained. The overproduction of the substrate for progesterone synthesis in the fetal compartment overloading the metabolic capacity in the placenta may be the reason why progesterone levels in both compartments depend on the localization of steroid converting enzymes as well as on the transport of steroids within the placenta. But these progesterone levels are independent of the short-term fluctuations of steroid levels within the opposite compartment as well as they are independent of moderate alterations in substrate (PregS) production. This may be a similar situation to the case of maternal LDL-cholesterol being a substrate for the "classical" placental progesterone synthesis. In contrast to the steroidogenesis in maternal adrenal, placental mitochondria have a near-saturating cholesterol concentration for P450scc. Thus cholesterol translocation to the P450scc is not a major site of the regulation of progesterone synthesis (Tuckey 2005).

According to our hypothesis, progesterone production may be at least partly provided by the most abundant product of the FZFA, PregS. Progesterone originating in the placenta may be selectively distributed into fetal and maternal compartments depending on the permeability of the placental membrane to steroids and the local distribution of $17 \beta$-hydroxysteroid dehydrogenases (17 $\beta$-HSD) determining the balance between progesterone and Prog20 $\alpha$ and, at the same time, the balance between estrone and estradiol. Microsomal type 2 $17 \beta$-HSD (17HSD2) catalyzes progesterone biosynthesis in the placenta from Prog20 $\alpha$ as well as inactivation of estradiol to estrone (Andersson and Moghrabi 1997). The effect of 17HSD2 is countered by types 5 and 7 17ß-HSDs (17HSD5 and 17HSD7, respectively) catalyzing progesterone deactivation to Prog20 $\alpha$, while estradiol is synthesized from estrone. Concerning the 17ß-hydroxysteroid dehydrogenase type 1 (17HSD1), this cytosolic enzyme shows a high specificity for C18 steroids converting inactive estrone to the active estrogen estradiol.

17HSD2 oxidizing estradiol to estrone and Prog20 $\alpha$ to progesterone is highly expressed in placental endothelial cells lining the fetal compartment (Drolet et al. 2007, Su et al. 2007). On the other side, syncytium, coming directly into contact with maternal blood, produces high amounts of estradiol. Reduction of the low activity estrogen, estrone, into the potent estrogen, estradiol, is catalyzed by 17HSD1. Syncytium is the major steroidogenic unit of the fetal term villi showing immunoreactivities with 17HSD1 mRNA and protein as well as P450scc, P450 aromatase and 3 $\beta$-HSD. Extravillous cytotrophoblasts (CTBs), e.g. those from which cell columns of anchoring villous originate, also express the 17HSD1 gene. However, CTBs lying beneath the syncytial layer, e.g. those from which syncytiotrophoblasts develop, contained barely detectable amounts of type 17HSD1 mRNA (Bonenfant et al. 2000). In contrast to type 17HSD1 mRNA, type 17HSD2 mRNA was not detectable in cell cultures of human cytotrophoblasts or syncytiotrophoblasts. The primary sites of the 17HSD2 gene expression are the endothelial cells of the villous arterioles.

As indicated by the aforementioned findings, the activation of progesterone synthesis by 17HSDs is probably closely associated with estradiol catabolism to estrone and vice versa.

This concept is supported by

- higher estrone/estradiol ratios (Kenny et al. 1973, Troisi et al. 2003) and higher progesterone/Prog20 $\alpha$ ratios in fetal circulation (Runnebaum et al. 1975) compared with the respective levels in maternal blood

- higher progesterone levels in fetal blood 
compared to maternal venous blood (Runnebaum et al. 1975, Antonipillai and Murphy 1977, Mathur et al. 1980, Farquharson and Klopper 1984, Hercz et al. 1988, Kawamura et al. 1989, Lofgren and Backstrom 1997)

- higher estradiol levels in maternal than in fetal circulation (Kenny et al. 1973, Troisi et al. 2003)

- higher estrone levels in fetal blood in comparison with those reported in maternal blood.

In the case of fetal estrogens the findings may be of physiological importance. As proposed by Drolet et al. (2007), 17HSD2 probably protects the fetus from the active estrogen.

Besides the placenta, the further potent steroidogenic cells expressing 17HSD2 are the hepatocytes (Moghrabi et al. 1997). It means that the fetal liver might also influence the balance between estrone and estradiol in both the fetal and maternal compartments. In addition, there are numerous other catabolic pathways, particularly the 16 $\alpha$-hydroxylation and sulfation, which may alter the balance between estrone and estradiol in mother and fetus.

\section{Evaluation of the hypothesis}

When considering the progressively increasing production of $\mathrm{CRH}$, which probably directly stimulates steroid biosynthesis in the FZFA, we can expect higher levels of progesterone in the fetus compared to maternal circulation due to excessive production of PregS synthesized in the FZFA. In accordance with the above mentioned concept, the higher progesterone levels in the human fetus than in the maternal compartment were reported by various authors (Runnebaum et al. 1975, Hercz et al. 1988, Lofgren and Backstrom 1997). Besides the primates, there are other mammalian species in which progesterone concentrations in fetal circulation are higher compared to the maternal blood (Barnes et al. 1975, Hagen et al. 1983). Among these studies the information reported by Hagen et al. (1983) may be of importance for placental progesterone biosynthesis in humans. These authors reported that the evident uptake of progesterone from the placenta by fetal blood in pig dams was not equivalent to the maternal uterine arterial-venous difference in progesterone concentration.

The possibility that maternal progesterone in humans may be synthesized from PregS of the fetal origin is substantiated by the results of Komatsuzaki et al. (1987). These authors administered deuterated PregS into maternal circulation and they found a certain amount of deuterated progesterone in the cord blood despite the unfavorable concentration gradient. Nevertheless, the penetration of maternal progesterone into the fetal compartment is not very important, as documented by the experiments of Escarcena et al. (1978) demonstrating that less than $10 \%$ of the hormone in fetal circulation is derived from the transfer of maternally circulating progesterone. The authors estimated that the secretion rate of the placental hormone towards the fetus would be about $10 \%$ of the progesterone secretion rate towards maternal circulation but only about $1 \%$ of the maternally circulating hormone was found to cross the placenta. It is obvious that the former findings, as well as the progesterone levels significantly higher in fetal circulation than those in maternal blood, contradict the suggestion of an exclusively maternal origin for progesterone in pregnancy.

Some studies indicate an association between the activity of FZFA and placental progesterone production, at least in the fetus. It was suggested that fetuses exposed to stress during labor produce higher progesterone secretion, which may protect the fetuses against the sequelae of hypoxia (Antonipillai and Murphy 1977, Shaxted et al. 1982). It is likely that the increasing fetal progesterone levels in stressful situations are associated with increased activity of the FZFA producing extreme amounts of PregS.

The association between activity of FZFA and maternal progesterone was also indicated by the data of Sagen et al. (1979), who measured concentrations of total estriol, progesterone, and cortisol in the blood from maternal cubital vein (MV) at regular intervals from the seventh week of pregnancy until the term in a woman with an anencephalic fetus. Except for the first trimester, during which the values were within the lower normal range, the concentration of estriol was constantly subnormal. Progesterone and human placental lactogen (HPL) were both within the low normal range and the "physiological" rise in cortisol levels was absent. The above mentioned data show that the absence of fetal pituitary results in the insensitivity of the definitive zone of fetal adrenal to stress. However, it is apparent that the function of the FZFA is reduced to some extent, but not completely eliminated. This conforms with the concept of direct stimulation of FZFA by placental CRH (Smith et al. 1998, Smith 2007). In contrast to Sagen et al. (1979), 
(Kawamura et al. (1989) reported that the levels of pregnenolone, Preg20 $\alpha$, Preg16 $\alpha$ and Prog20 $\alpha$ in MV in the third trimester were pronouncedly lower in the case of anencephalic pregnancy than in normal pregnancy, while progesterone levels showed no significant difference. The latter data indicate that the interplay between fetal pituitary and FZFA is important, but placental progesterone production is largely autonomous. The considerable autonomy of placental progesterone synthesis, which might prefer the "classic" mechanism of progesterone synthesis in the case of insufficient PregS availability, was also demonstrated in the studies on anencephalic or dead fetuses (Dawood 1976, MacDonald et al. 1982).

Hercz et al. (1988) demonstrated that progesterone production depends on gestational age. The authors reported that the progesterone concentration at labor increased during the $28^{\text {th }}-40^{\text {th }}$ weeks in MV but grew only during $28^{\text {th }}-36^{\text {th }}$ weeks in UVn and UA and then fell significantly by the $40^{\text {th }}$ week. Alternatively, Donaldson et al. (1991) reported no significant change in the fetal serum levels of progesterone with gestational age in the samples obtained by transabdominal puncture within the $18^{\text {th }}$ and $41^{\text {st }}$ weeks of gestation. In the fetus there was a significant correlation between progesterone and cortisol concentrations. These results confirmed high levels of progesterone in the fetus from an early stage of gestation, and provided evidence for placental progesterone being the precursor of fetal cortisol. However, the alternative explanation for the correlation between fetal cortisol and progesterone might be the simultaneous effect of CRH on the fetal pituitary and FZFA. Kawamura et al. (1989) showed that the concentrations of the total 3 $\beta$-hydroxy-5-ene steroids (including sulfates) in MV progressively increase up to the delivery. Progesterone and Prog20 $\alpha$ showed a gradual increase from the first trimester to maximum levels at the pre-pain period followed by a rapid decrease at delivery. The concurrent dependence of progesterone levels in the maternal and the levels of progesterone and $3 \beta$-hydroxy5 -ene steroids in the fetal compartments on gestational age indicate that there may be relationships between the activity of FZFA and the steroid levels in both compartments, although the fluctuations in FZFA activity may not be immediately reflected by changing progesterone levels in maternal compartment.

Concerning our idea about the association between catabolism of progesterone and the biosynthesis of estradiol via the system of placental and perhaps liver
17 $\beta$-HSD, a different concept is generally accepted. Shanker and Rao (1997) demonstrated that there is a regulating mechanism for progesterone synthesis dependent on estrogen and progesterone receptors. Waddell et al. (1996) suggest that the estrogen-dependent developmental increase in key components of the progesterone biosynthetic pathway in baboons is associated with a corresponding increase in progesterone production. However, the above noted data concerning the estradiol effect on progesterone synthesis may be explained alternatively. FZFA concurrently produces precursors for estrogen and progesterone placental synthesis. Progesterone and estrone reversible interconversion to Prog $20 \alpha$ and estradiol, respectively, might be catalyzed mostly by the same enzymes.

\section{Subjects and methods}

\section{Subjects}

The study group consisted of 50 women (from 21 to 41 years) in labor from the $28^{\text {th }}$ to the $41^{\text {st }}$ week of gestation. Twelve $(24 \%)$ women giving birth after the $38^{\text {th }}$ week of gestation were without perinatological complications. From the 38 (76 \%) labors coming on within the $28^{\text {th }}$ and $37^{\text {th }}$ weeks of gestation, $29(76.3 \%)$ pregnancies were terminated by Caesarean section due to health risks to mother or fetus and $9(23.7 \%)$ were vaginal deliveries with spontaneous uterine activity. In the case of these women, the reason for premature uterine activity was infection in the mother. In contrast to the group of healthy women after the $38^{\text {th }}$ week of gestation, all premature births were selected so that the reason for premature uterine activity was independent of steroid status. The local Ethical Committee approved the study. After giving written consent, the patients underwent sample collection.

\section{Sample collection}

Samples of blood from umbilical vein and maternal cubital vein were withdrawn immediately after the separation of a newborn from the umbilical cord. Each sample was collected into a cooled plastic tube. The plasma was obtained after centrifugation for $5 \mathrm{~min}$ at $2000 \mathrm{~g}$ at $4{ }^{\circ} \mathrm{C}$. The samples of plasma were stored at $-20{ }^{\circ} \mathrm{C}$ until analyzed.

\section{Chemicals and reagents}

The steroids were purchased from Steraloids (Newport, RI, USA), the Sylon B from Supelco 
Table 1. Temperature gradients used for steroid analysis at constant linear velocity $60 \mathrm{~cm} \cdot \mathrm{s}^{-1}$.

\begin{tabular}{|c|c|c|c|c|c|c|c|}
\hline \multirow{2}{*}{$\begin{array}{c}\text { Method } \\
G 1, G 3, G C 3\end{array}$} & \multicolumn{4}{|c|}{$\begin{array}{c}\text { Step } \\
\text { Initial conditions (final temperature, temperature } \\
\text { gradient, hold time) } \\
{\left[{ }^{\circ} \mathbf{C},{ }^{\circ} \mathbf{C} \cdot \min -1, \text { min }\right]}\end{array}$} & \multirow{2}{*}{$\begin{array}{c}\begin{array}{c}\text { Initial } \\
\text { pressure } \\
{[\mathrm{kPa}]}\end{array} \\
34\end{array}$} & \multirow{2}{*}{ 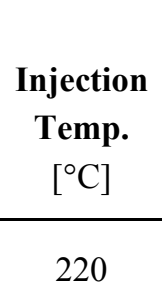 } & \multirow{2}{*}{$\begin{array}{c}\begin{array}{c}\text { Overal } \\
\text { time } \\
{[\mathrm{min}]}\end{array} \\
18.25\end{array}$} \\
\hline & $80(-, 1)$ & $190(40,0)$ & $210(4,0)$ & $300(20,5)$ & & & \\
\hline G2 & $80(-, 0)$ & $190(40,0)$ & $205(1.6,0)$ & $300(40,5)$ & 34 & 240 & 19.50 \\
\hline
\end{tabular}

Table 2. Characteristics from the analysis of 69 steroids and steroid polar conjugates in the plasma from umbilical artery, umbilical vein and maternal cubital vein and in amniotic fluid at labor from $28^{\text {th }}$ to $41^{\text {st }}$ week of pregnancy.

\begin{tabular}{|c|c|c|c|c|c|c|c|}
\hline \multirow{2}{*}{$\begin{array}{c}\text { Gradient } \\
G 1\end{array}$} & \multirow{2}{*}{$\begin{array}{l}\text { Steroid } \\
\text { EpiE2 (IS) }\end{array}$} & \multirow{2}{*}{$\begin{array}{c}\mathbf{m} / \mathbf{z} \\
{[\mathbf{D a}]}\end{array}$} & \multicolumn{2}{|c|}{ Retention time [min] } & \multicolumn{2}{|c|}{$\begin{array}{c}\text { Peak range for } \\
\text { quantitative peak } \\
\text { [min] }\end{array}$} & \multirow{2}{*}{$\begin{array}{c}\boldsymbol{\sigma} \\
0.011\end{array}$} \\
\hline & & & $\underline{9.97}$ & ---- & 9.91 & -10.02 & \\
\hline G1 & P5 $\beta$ & $275,288, \underline{343}$ & 11.88 & $\underline{11.90}$ & 11.89 & - $\quad 11.94$ & 0.009 \\
\hline G1 & $\mathrm{P} 5 \alpha$ & $275,288, \underline{\underline{343}}$ & $\underline{12.15}$ & $\overline{12.17}$ & 12.11 & $-\quad 12.17$ & 0.008 \\
\hline$G 2$ & Prog & $273, \underline{286}, 372,341$ & $\overline{14.51}$ & 14.58 & 14.47 & -14.54 & 0.007 \\
\hline$G 3$ & EpiE2 (IS) & $285, \underline{416}$ & $\overline{9.97}$ & ---- & 9.92 & $-\quad 10.02$ & 0.011 \\
\hline$G 3$ & $\mathrm{P} 5 \beta 20 \alpha$ & $288, \underline{303}$ & 11.34 & $\underline{11.36}$ & 11.35 & -11.42 & 0.008 \\
\hline G3 & $\mathrm{P} 5 \alpha 20 \alpha$ & $288, \underline{\underline{303}}$ & 11.64 & $\underline{11.66}$ & 11.65 & -11.71 & 0.008 \\
\hline G3 & $\operatorname{Prog} 20 \alpha$ & $153,296, \underline{301}$ & $\underline{11.85}$ & 11.97 & 11.81 & $-\quad 11.88$ & 0.008 \\
\hline$G 3 C$ & EpiE2 (IS) & $231,285, \underline{416}$ & $\overline{9.98}$ & ---- & 9.94 & -10.03 & 0.011 \\
\hline$G 3 C$ & $\mathrm{P} 5 \beta 20 \alpha \mathrm{C}$ & $288, \underline{303}$ & $\overline{11.35}$ & $\underline{11.37}$ & 11.36 & -11.42 & 0.009 \\
\hline$G 3 C$ & $\mathrm{P} 5 \alpha 20 \alpha \mathrm{C}$ & $288, \underline{\underline{303}}$ & $\underline{11.65}$ & $\overline{11.67}$ & 11.62 & -11.66 & 0.009 \\
\hline$G 3 C$ & Prog $20 \alpha C$ & $153,296, \underline{301}$ & 11.86 & 11.98 & 11.82 & -11.90 & 0.009 \\
\hline
\end{tabular}

Peaks and effective masses used for quantification are underlined, $\sigma . .$. standard deviation of retention time for quantitation peak.

(Bellefonte, PA, USA), the methoxylamine hydrochloride from Sigma (St. Louis, MO, USA) and the solvents from Merck (Darmstadt, Germany).

\section{Instruments}

The GC-MS system was supplied by Shimadzu (Kyoto, Japan). The GCMS-QP2010 Plus system consisted of a gas chromatograph equipped with automatic flow control, AOC-20s autosampler and a quadrupole electron-impact detector with an adjustable electron voltage of $10-195 \mathrm{~V}$, which was set-up to a $70 \mathrm{~V}$. A capillary column with a medium polarity RESTEK Rxi (diameter $0.25 \mathrm{~mm}$, length $15 \mathrm{~m}$, film thickness $0.1 \mu \mathrm{m}$ was used for analyses).

\section{Steroid analysis}

The levels of progesterone, $5 \alpha / \beta$-dihydro- progesterones and their 20 $\alpha$-hydroxy-metabolites including polar conjugates of $20 \alpha$-hydroxy-metabolites were obtained in the frame of metabolomic study including 40 unconjugated steroids and 29 steroid polar conjugates measured in the maternal and fetal body fluids using GC-MS. The samples were prepared using the approach reported previously for preparation of methoxylamine-trimethylsilyl derivatives of progesterone and $5 \alpha / \beta$-dihydroprogesterones (Hill et al. 2007). The polar conjugates of Prog $20 \alpha$ were prepared after hydrolysis as described ibidem.

\section{Instrument setup}

Electron-impact ionization was used for the analyses. The electron voltage was set up to $70 \mathrm{~V}$ and the emission current to $160 \mu \mathrm{A}$. The temperatures of the injection port, ion source and interface were maintained 
A
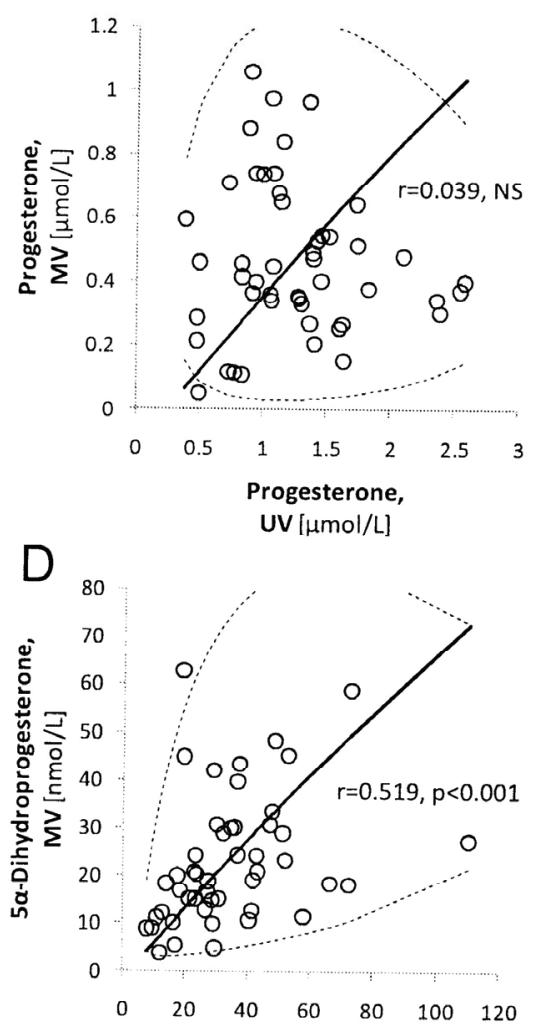

5a-Dihydroprogesterone,

UV $[\mathrm{nmol} / \mathrm{L}]$

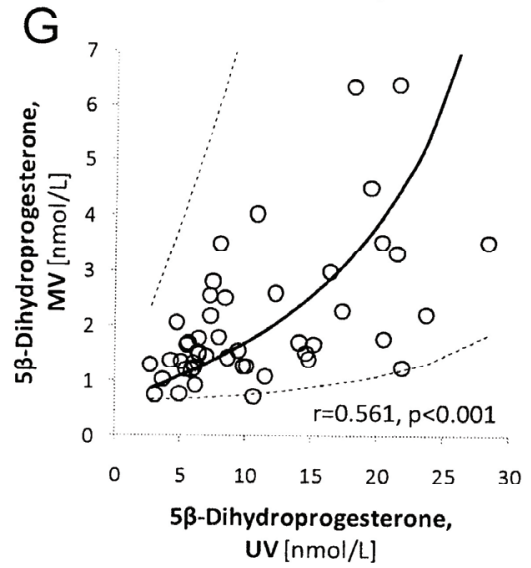

B

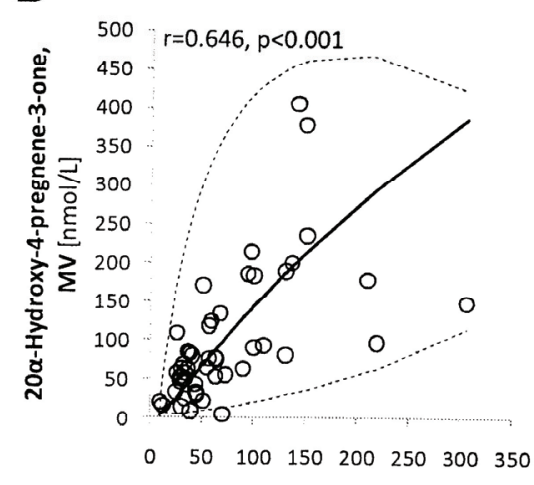

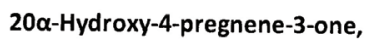
UV [nmol/L]

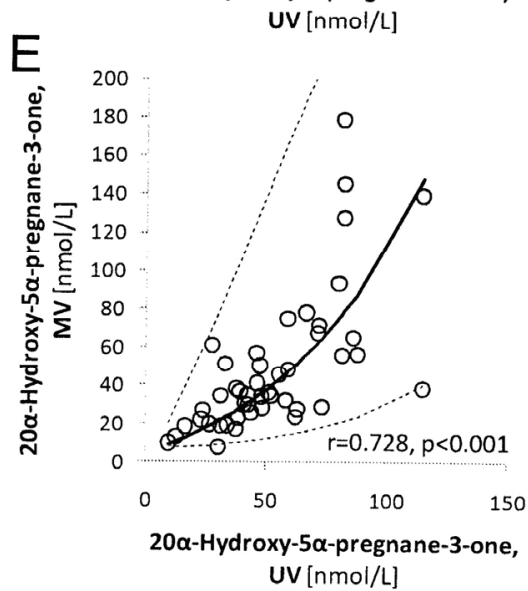

$\mathrm{H}$

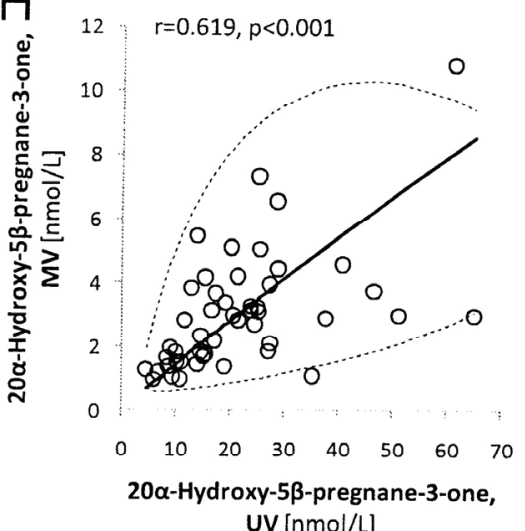

C

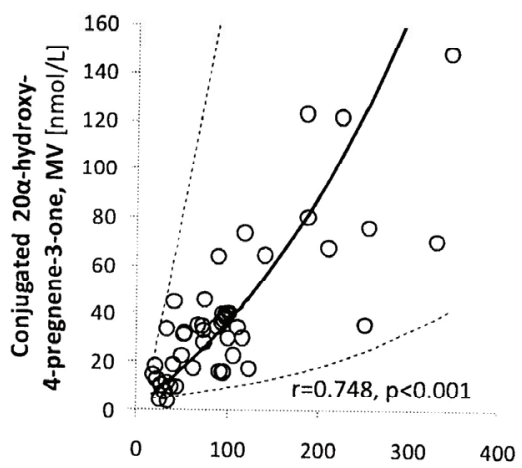

Conjugated 20a-hydroxy-

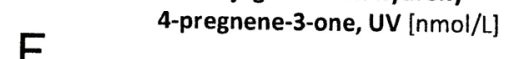

F
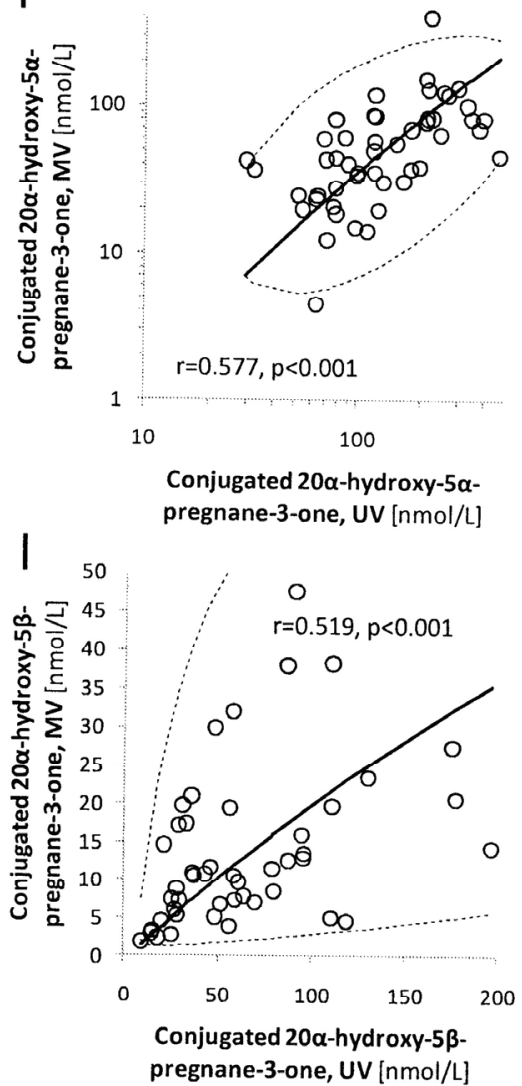

Fig. 1. Relationships between steroids in the fetal umbilical venous blood (UV) and maternal cubital venous blood (MV) for the levels of

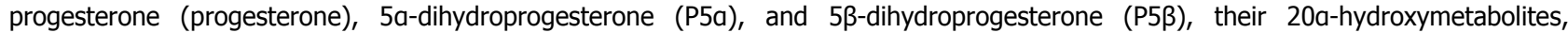
20a hydroxy-4-pregnene-3-one (Prog20a), 20a-hydroxy-5a-pregnane-3-one (P5a20a), and 20a-hydroxy-5 $\beta$-pregnane-3-one (P5 $320 a)$, and polar conjugates of the 20a-hydroxy-steroids (Prog20aC, P5a20aC, P5320aC). The bold full curve represents the principal axis after retransformation to original scale, while the thin dashed line is the retransformed $95 \%$ confidence ellipsoid. The correlation coefficient $r$ is calculated from the data transformed by a power transformation to attain Gaussian data distribution and a constant variance. For details see Statistical data analysis.

samples. The mixtures were specific for each of the independent courses as mentioned above. The standards were injected in duplicates in three different amounts for each steroid (10, 100 and $1000 \mathrm{pg}$ ). Respecting the excellent linearity for all substances investigated (the correlation coefficients of two-parameter linear regression ranged from 0.9971 to 0.9999 ); the calibration line was used for data processing.

\section{Statistical data analysis}

To eliminate skewed data distribution and heteroscedasticity, the original data was transformed to a Gaussian distribution and a constant variance before further processing by a power transformation. 
Relationships between steroid levels were evaluated using Pearson's correlations and partial correlations with an adjustment to constant levels of all the variables in the correlation matrix except for the pair under investigation. The differences between compartments and individual steroids were evaluated using a robust Wilcoxon's paired test. Statistical software Statgraphics Centurion, version XV from Statpoint Inc. (Herndon, Virginia, USA) was used for data analysis.

\section{Results}

The levels of progesterone and its $5 \alpha / \beta$ 3 -oxo/20 $\alpha$-metabolites found in the group of 12 women in normal labor within the $38^{\text {th }}$ and $41^{\text {st }}$ weeks of gestation are shown in Table 3. There is also a comparison of our results with the data reported from other studies (Csapo et al. 1971, Booth and El-Garf 1974, Arai and Yanaihara 1977, Coats et al. 1977, Buster et al. 1979, O'Leary et al. 1991, Luisi et al. 2000, Pearson Murphy et al. 2001, Gilbert Evans et al. 2005, Sheehan et al. 2005, Soldin et al. 2005). The steroid levels generally agreed with the data reported elsewhere (Runnebaum et al. 1975, Buster et al. 1979, Kawamura et al. 1989, Lofgren and Backstrom 1997, Pearson Murphy et al. 2001, Gilbert Evans et al. 2005, Sheehan et al. 2005, Hill et al. 2007). A few discrepancies between our data and previously reported results may be explained by differences in sample collection. Several 20a-hydroxyC21-steroids and their conjugates were measured in UVn and/or MV for the first time. We have also found no previous data concerning the levels of P5 $\beta$ in UVn. Progesterone levels were significantly higher in UVn than in MV (3.7 times).

As expected, in accordance with previously reported data (Oszczygiel 1975, Mathur et al. 1980, Farquharson and Klopper 1984, Hercz et al. 1988), progesterone levels did not correlate between MV and UVn (Fig. 1A, Table 4). On the other hand, all the investigated metabolites of progesterone showed significant associations between MV and UVn (Figs 1B1I, Table 4).

As demonstrated in Table 4, the partial correlations with adjustment to constant levels of all remaining steroids except for the pair of the steroids investigated (below the diagonal) confirmed that progesterone in MV was actually independent of progesterone in UVn. However, both Prog20 $\alpha$ and Prog20 $\alpha$ C significantly correlated between UVn and MV, while progesterone and Prog20 $\alpha$ correlated positively within MV. Similar situation was observed for correlations of $\mathrm{P} 5 \alpha, \quad \mathrm{P} 5 \beta$ and their respective 20a-hydroxymetabolites.

\section{Discussion}

The above stated data demonstrate that there is an association between maternal and fetal steroids, although the relations are not straightforward. Instead of a direct relationship between maternal and fetal progesterone, there is a relatively close association between the two compartments for its 20a-hydroxymetabolite. There are at least two explanations for the partial correlations mentioned above. The findings may indicate that, at least in progesterone and P5 $\alpha$, the parent

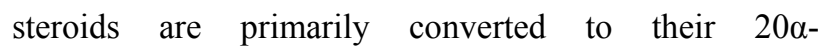
hydroxymetabolites in the placenta, and then they penetrate from the placenta to the fetal and maternal compartments. There they may again be reconstituted to the parent 20-oxo-steroids. In contrast to progesterone and P $5 \alpha$, the P5 $\beta$ may significantly penetrate in the form of the parent 20-oxo-steroid, without primary conversion to $\mathrm{P} 5 \beta 20 \alpha / \mathrm{C}$. Nevertheless, even in this case the conversion of $\mathrm{P} 5 \beta$ to $\mathrm{P} 5 \beta 20 \alpha / \mathrm{C}$ in the fetus, penetration of the substances into the maternal compartment, and reconstitution of $\mathrm{P} 5 \beta 20 \alpha / \mathrm{C}$ to $\mathrm{P} 5 \beta$ herein, are also probable.

The second, and more probable, hypothesis suggesting a different localization of individual 17ß-HSDs types in the placenta, which may be simultaneously decisive for Prog20 $\alpha /$ progesterone and estrone/estradiol ratios in fetal and maternal compartments, has already been mentioned. As shown in Table 3, the Prog20 $\alpha$ levels are similar in fetal and maternal blood, while progesterone levels are almost four times higher in the umbilical vein.

Respecting the aforesaid hypothesis, the results given above are consistent with the situation in estrogens. Estradiol blood levels are about 2.5 times higher in the mother than in the fetus, while estrone levels are about four times higher in fetal blood than in the maternal circulation. These data clearly support our hypothesis that the localization of 17HSD2 oxidizing estradiol to estrone and Prog $20 \alpha$ to progesterone, which is highly expressed in placental endothelial cells lining the fetal compartment (Drolet et al. 2007, Su et al. 2007), and alternatively syncytium, which is directly in contact with maternal blood and produces high amounts of estradiol due to the 


\begin{tabular}{|c|c|c|c|c|c|c|c|c|c|}
\hline \multicolumn{3}{|l|}{ 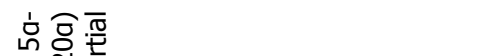 } & \multicolumn{7}{|c|}{ 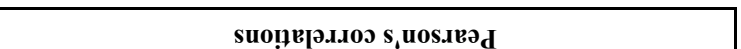 } \\
\hline \multirow{6}{*}{ 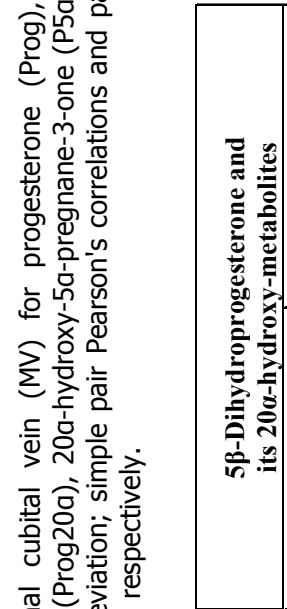 } & \multirow{6}{*}{$\begin{array}{l} \\
\\
0 \\
0\end{array}$} & $\partial^{p 0 z^{80} 0 . I_{d}}$ & 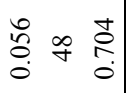 & 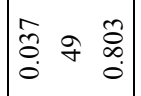 & 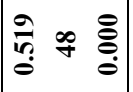 & $\stackrel{\widetilde{\sigma}}{\circ} \stackrel{\infty}{\stackrel{\sigma}{\sigma}}$ & 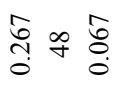 & & \\
\hline & & $n_{00 z 0} 0 x_{d}$ & $\begin{array}{l}\infty \\
0 \\
0 \\
0\end{array}$ & 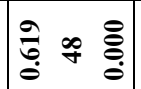 & 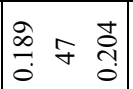 & 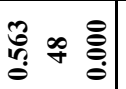 & & 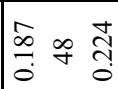 & \\
\hline & & so.td & 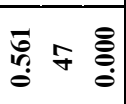 & 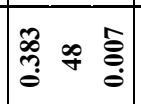 & 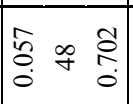 & & 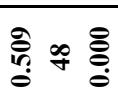 & $\mid \begin{array}{l}\overrightarrow{0} \\
0 \\
0\end{array}$ & \\
\hline & & $\rho^{p 00} z^{800} \cdot d_{d}$ & 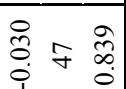 & 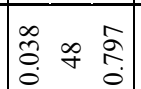 & & \begin{tabular}{ccc}
$\hat{f}$ & $\infty$ & $\overrightarrow{0}$ \\
\hdashline & + & 0 \\
0
\end{tabular} & 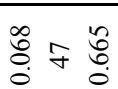 & 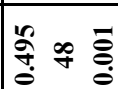 & \\
\hline & & 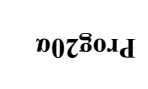 & 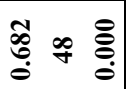 & & 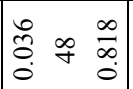 & 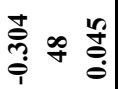 & 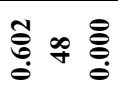 & 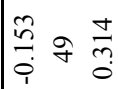 & \\
\hline & & so. $_{d}$ & & $\begin{array}{lll}\stackrel{\infty}{0} \\
\stackrel{0}{0} & \stackrel{\infty}{+} & \stackrel{0}{0}\end{array}$ & 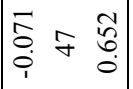 & तై & 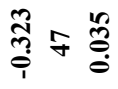 & $\overbrace{0}^{a} \begin{array}{c}\infty \\
0\end{array}$ & \\
\hline 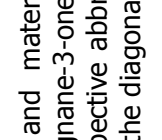 & & & 垈 & & 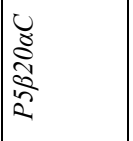 & 2 & 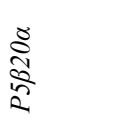 & 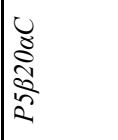 & \\
\hline & & $\partial^{n_{0} z^{0} 0 . I_{\mathbf{d}}}$ & $\begin{array}{l}\text { fy } \\
0 \\
0\end{array}$ & 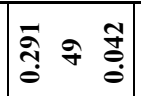 & 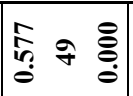 & 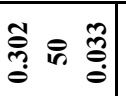 & 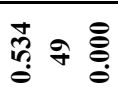 & & \\
\hline & 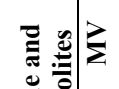 & $n_{00 z 0 . x_{d}}$ & 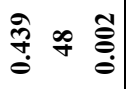 & 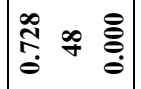 & 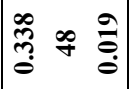 & 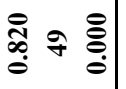 & & 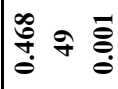 & \\
\hline & . & so.. & 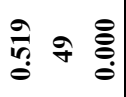 & 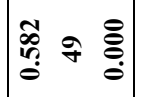 & 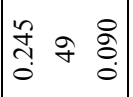 & & 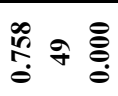 & 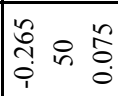 & \\
\hline & 穿 & $\rho^{p_{0} z^{-80} 0 . I_{\mathbf{d}}}$ & 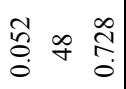 & 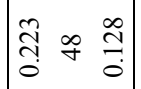 & & 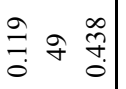 & 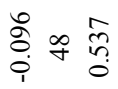 & $\overbrace{0}^{0} \frac{1}{0}$ & \\
\hline & 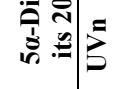 & nozô. $_{0}$ & 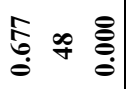 & & 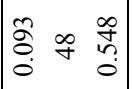 & 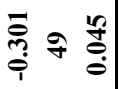 & 离 & 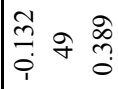 & \\
\hline 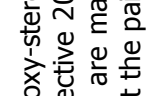 & & so. $_{d}$ & & 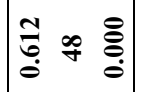 & 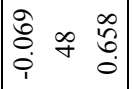 & 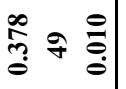 & 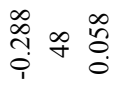 & 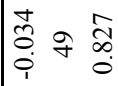 & \\
\hline 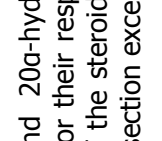 & & & 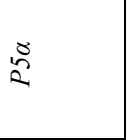 & 气ัّ & & 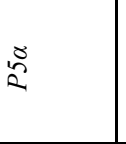 & 壱 & 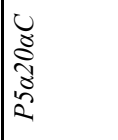 & \\
\hline 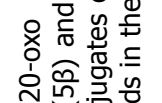 & & $\partial^{n_{0} z^{800} 0 . I_{\mathbf{d}}}$ & $\begin{array}{lll}\overrightarrow{\vec{n}} & \infty & 0 \\
0 & + & 0 \\
0 & 0\end{array}$ & 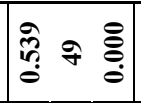 & 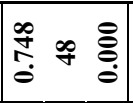 & 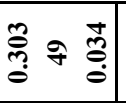 & 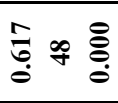 & & \\
\hline $\begin{array}{c}\bar{y} \\
\text { y. }\end{array}$ & 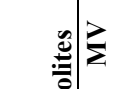 & 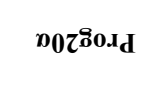 & 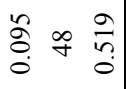 & 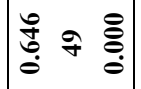 & $\left|\begin{array}{ccc}\hat{N} & \infty & 0 \\
& \infty \\
\hdashline & + & 0 \\
\hdashline\end{array}\right|$ & 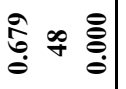 & & 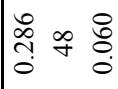 & \\
\hline $\begin{array}{l}0.00 \\
0 \\
0 \\
0 \\
0 \\
0\end{array}$ & 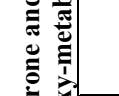 & ${ }_{\text {so. }}$ & 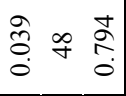 & 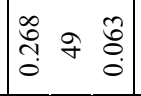 & $\left|\begin{array}{ccc}\infty & \infty \\
\hdashline & \infty & 0 \\
0 & + & 0 \\
0\end{array}\right|$ & & \begin{tabular}{lll}
$\stackrel{0}{0}$ \\
$\stackrel{0}{0}$ \\
\hdashline
\end{tabular} & 总 & \\
\hline 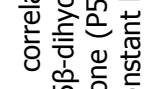 & : & $\rho^{n_{0} z^{-80} 0 . I_{\mathbf{d}}}$ & 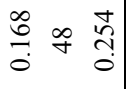 & 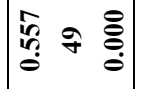 & & 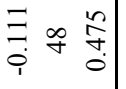 & 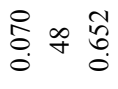 & 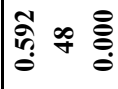 & \\
\hline 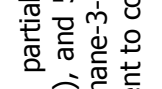 & $\begin{array}{c}\bar{N} \\
:= \\
:\end{array}$ & nozô. $_{0}$ & $\begin{array}{c}\partial े \\
\frac{\partial}{0}\end{array}$ & & 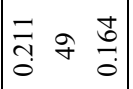 & 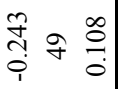 & 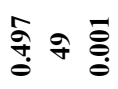 & 宮 & \\
\hline $\bar{a}$ & & so.xd & & 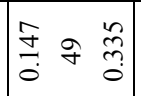 & 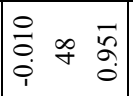 & 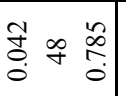 & 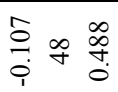 & 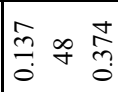 & \\
\hline 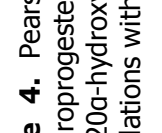 & & & 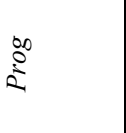 & 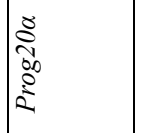 & 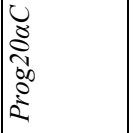 & $\underbrace{\infty}$ & 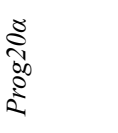 & 离 & \\
\hline & & & & $\Lambda \cap$ & & & $\Lambda W$ & & \\
\hline
\end{tabular}


effects of 17HSD1, 17HSD5, and 17HSD7 (Andersson and Moghrabi 1997), are responsible for the higher proportion of the oxidized form of the sex hormones in the fetus, but a higher proportion of the reduced form of these substances in maternal vein.

The consequences of our hypothesis are obvious. The estradiol role in the maternal compartment is widely known. On the other hand, the possibility that high progesterone levels in the fetal compartment may provide a substrate pool for the synthesis of neuroprotective $3 \alpha$-hydroxy- $5 \alpha / \beta$-pregnane-20-oxo metabolites which easily penetrate to the fetal brain and may protect the brain neuronal cells from oxidative damage. This hypothesis was quite recently documented by several latest studies (Billiards et al. 2006, Hirst et al. 2006,
2008, Yawno et al. 2007, Westcott et al. 2008). The practical consequence of the suggested mechanism may be helpful in the effort to develop the substances, which may influence the placental production of progesterone and, in turn, the synthesis of neuroprotective substances in the fetus, as well as in obtaining the tools enabling to control of the timing of parturition and the onset of labor.

\section{Conflict of Interest}

There is no conflict of interest.

\section{Acknowledgements}

This study was supported by the grant of GA ČR 303/06/1817.

\section{References}

ANDERSSON S, MOGHRABI N: Physiology and molecular genetics of 17 beta-hydroxysteroid dehydrogenases. Steroids 62: 143-147, 1997.

ANTONIPILLAI I, MURPHY BE: Serum oestrogens and progesterone in mother and infant at delivery. Br J Obstet Gynaecol 84: 179-185, 1977.

ARAI K, YANAIHARA T: Steroid hormone changes in fetal blood during labor. Am J Obstet Gynecol 127: 879-883, 1977.

BARNES RJ, NATHANIELSZ PW, ROSSDALE PD, COMLINE RS, SILVER M: Plasma progestagens and oestrogens in fetus and mother in late pregnancy. J Reprod Fertil Suppl 23: 617-623, 1975.

BILLIARDS SS, NGUYEN PN, SCHEERLINCK JP, PHILLIPS DJ, CANNY BJ, WALKER DW, HIRST JJ: Hypoxia potentiates endotoxin-induced allopregnanolone concentrations in the newborn brain. Biol Neonate 90: 258$267,2006$.

BOGUSLAWSKI W: Cytochrome P-450 and steroidogenic activities of the human placental mitochondria. $J$ Steroid Biochem 18: 771-775, 1983.

BONENFANT M, PROVOST PR, DROLET R, TREMBLAY Y: Localization of type 1 17beta-hydroxysteroid dehydrogenase mRNA and protein in syncytiotrophoblasts and invasive cytotrophoblasts in the human term villi. $J$ Endocrinol 165: 217-222, 2000.

BOOTH M, EL-GARF TA: Plasma progesterone concentration during the third trimester of diabetic pregnancy. J Obstet Gynaecol Br Commonw 81: 768-776, 1974.

BRAUNSTEIN GD: Endocrinology of the life span. In: Williams Textbook of Endocrinology. PR LARSEN (ed.), W.B. Saunders Company, Philadelphia, 2003, 799 pp.

BUSTER JE, CHANG RJ, PRESTON DL, ELASHOFF RM, COUSINS LM, ABRAHAM GE, HOBEL CJ, MARSHALL JR: Interrelationships of circulating maternal steroid concentrations in third trimester pregnancies. I. C21 steroids: progesterone, 16 alpha-hydroxyprogesterone, 17 alpha-hydroxyprogesterone, 20 alpha-dihydroprogesterone, delta 5-pregnenolone, delta 5-pregnenolone sulfate, and 17-hydroxy delta 5-pregnenolone. J Clin Endocrinol Metab 48: 133-138, 1979.

CARR BR, SIMPSON ER: Cholesterol synthesis in human fetal tissues. J Clin Endocrinol Metab 55: 447-452, 1982.

COATS P, WALKER E, YOUSSEFNEJADIAN E, CRAFT IL: Variations in plasma steroid and prostaglandin concentrations during human pregnancy. Acta Obstet Gynecol Scand 56: 453-457, 1977.

CSAPO AI, KNOBIL E, VAN DER MOLEN HJ, WIEST WG: Peripheral plasma progesterone levels during human pregnancy and labor. Am J Obstet Gynecol 110: 630-632, 1971. 
DAWOOD MY: Circulating maternal serum progesterone in high-risk pregnancies. Am J Obstet Gynecol 125: 832-840, 1976.

DONALDSON A, NICOLINI U, SYMES EK, RODECK CH, TANNIRANDORN Y: Changes in concentrations of cortisol, dehydroepiandrosterone sulphate and progesterone in fetal and maternal serum during pregnancy. Clin Endocrinol (Oxf) 35: 447-451, 1991.

DROLET R, SIMARD M, PLANTE J, LABERGE P, TREMBLAY Y: Human type 217 beta-hydroxysteroid dehydrogenase mRNA and protein distribution in placental villi at mid and term pregnancy. Reprod Biol Endocrinol 5: 30, 2007.

ELLIS MJ, LIVESEY JH, INDER WJ, PRICKETT TC, REID R: Plasma corticotropin-releasing hormone and unconjugated estriol in human pregnancy: gestational patterns and ability to predict preterm delivery. $A m J$ Obstet Gynecol 186: 94-99, 2002.

ESCARCENA L, CLARK H, GURPIDE E: Contribution of maternal circulation to blood-borne progesterone in the fetus. I. Studies on human subjects. Am J Obstet Gynecol 130: 462-465, 1978.

FARQUHARSON RG, KLOPPER AI: Progesterone concentrations in maternal and fetal blood. Br J Obstet Gynaecol 91: 133-137, 1984.

GILBERT EVANS SE, ROSS LE, SELLERS EM, PURDY RH, ROMACH MK: 3alpha-reduced neuroactive steroids and their precursors during pregnancy and the postpartum period. Gynecol Endocrinol 21: 268-279, 2005.

GOLAND RS, JOZAK S, WARREN WB, CONWELL IM, STARK RI, TROPPER PJ: Elevated levels of umbilical cord plasma corticotropin-releasing hormone in growth-retarded fetuses. J Clin Endocrinol Metab 77: 11741179, 1993.

HAGEN DR, HOUTZ SK, GRIEL LC JR, KAVANAUGH JF: Concentrations of progesterone in arterial and venous plasma of fetal pigs and their dams in late gestation. Biol Reprod 29: 919-923, 1983.

HAVLÍKOVÁ H, HILL M, HAMPL R, STÁRKA L: Sex- and age-related changes in epitestosterone in relation to pregnenolone sulfate and testosterone in normal subjects. J Clin Endocrinol Metab 87: 2225-2231, 2002.

HERCZ P, UNGAR L, SIKLOS P: Perinatal progesterone in maternal-fetoplacental system during mature and premature deliveries. Acta Obstet Gynecol Scand 67: 233-235, 1988.

HILL M, CIBULA D, HAVLÍKOVÁ H, KANCHEVA L, FAIT T, KANCHEVA R, PAŘÍZEK A, STÁRKA L: Circulating levels of pregnanolone isomers during the third trimester of human pregnancy. $J$ Steroid Biochem Mol Biol 105: 166-175, 2007.

HIRST JJ, YAWNO T, NGUYEN P, WALKER DW: Stress in pregnancy activates neurosteroid production in the fetal brain. Neuroendocrinology 84: 264-274, 2006.

HIRST JJ, PALLISER HK, YATES DM, YAWNO T, WALKER DW: Neurosteroids in the fetus and neonate: potential protective role in compromised pregnancies. Neurochem Int 52: 602-610, 2008.

HOBEL CJ, DUNKEL-SCHETTER C, ROESCH SC, CASTRO LC, ARORA CP: Maternal plasma corticotropinreleasing hormone associated with stress at 20 weeks' gestation in pregnancies ending in preterm delivery. $\mathrm{Am}$ J Obstet Gynecol 180: S257-S263, 1999.

KAWAMURA E, HASHINO M, AKIYAMA T, KOSAKI T, YANAIHARA T, NAKAYAMA T, MORI H, YAMAGUCHI T: Serum concentrations of delta 5C21 steroids during pregnancy and at delivery (in Japanese). Nippon Naibunpi Gakkai Zasshi 65: 42-54, 1989.

KENNY FM, ANGSUSINGHA K, STINSON D, HOTCHKISS J: Unconjugated estrogens in the perinatal period. Pediatr Res 7: 826-831, 1973.

KERESZTES P, AYERS JW, MENON KM, ROMANI T: Comparison of peripheral, uterine and cord estrogen and progesterone levels in laboring and nonlaboring women at term. J Reprod Med 33: 691-694, 1988.

KOMATSUZAKI K, KOSAKI T, HASHINO M, YANAIHARA T, NAKAYAMA T, MORI H: [Metabolism of pregnenolone sulfate in feto-placental unit]. Nippon Sanka Fujinka Gakkai Zasshi 39: 1095-1102, 1987.

LAATIKAINEN T, PELKONEN J, APTER D, RANTA T: Fetal and maternal serum levels of steroid sulfates, unconjugated steroids, and prolactin at term pregnancy and in early spontaneous labor. $J$ Clin Endocrinol Metab 50: 489-494, 1980. 
LI Y, ISOMAA V, PULKKA A, HERVA R, PELTOKETO H, VIHKO P: Expression of 3beta-hydroxysteroid dehydrogenase type 1, P450 aromatase, and 17beta-hydroxysteroid dehydrogenase types 1, 2, 5 and 7 mRNAs in human early and mid-gestation placentas. Placenta 26: 387-392, 2005.

LOFGREN M, BACKSTROM T: High progesterone is related to effective human labor. Study of serum progesterone and 5alpha-pregnane-3,20-dione in normal and abnormal deliveries. Acta Obstet Gynecol Scand 76: 423-430, 1997.

LUISI S, PETRAGLIA F, BENEDETTO C, NAPPI RE, BERNARDI F, FADALTI M, REIS FM, LUISI M, GENAZZANI AR: Serum allopregnanolone levels in pregnant women: changes during pregnancy, at delivery, and in hypertensive patients. J Clin Endocrinol Metab 85: 2429-2433, 2000.

MACDONALD PC, CUTRER S, MACDONALD SC, CASEY ML, PARKER CR JR: Regulation of extraadrenal steroid 21-hydroxylase activity. Increased conversion of plasma progesterone to deoxycorticosterone during estrogen treatment of women pregnant with a dead fetus. J Clin Invest 69: 469-478, 1982.

MATHUR RS, LANDGREBE S, MOODY LO, POWELL S, WILLIAMSON HO: Plasma steroid concentrations in maternal and umbilical circulation after spontaneous onset of labor. J Clin Endocrinol Metab 51: 1235-1238, 1980.

MCLEAN M, BISITS A, DAVIES J, WOODS R, LOWRY P, SMITH R: A placental clock controlling the length of human pregnancy. Nat Med 1: 460-463, 1995.

MILLER WL: Steroid hormone biosynthesis and actions in the materno-feto-placental unit. Clin Perinatol 25: 799-817, $\mathrm{v}, 1998$.

MOGHRABI N, HEAD JR, ANDERSSON S: Cell type-specific expression of 17 beta-hydroxysteroid dehydrogenase type 2 in human placenta and fetal liver. J Clin Endocrinol Metab 82: 3872-3878, 1997.

NODWELL A, CARMICHAEL L, FRASER M, CHALLIS J, RICHARDSON B: Placental release of corticotrophinreleasing hormone across the umbilical circulation of the human newborn. Placenta 20: 197-202, 1999.

O'LEARY P, BOYNE P, FLETT P, BEILBY J, JAMES I: Longitudinal assessment of changes in reproductive hormones during normal pregnancy. Clin Chem 37: 667-672, 1991.

OSZCZYGIEL VA: Pregnandiol and progesterone in the umbilical cord blood in comparison with the level of both hormones in the maternal peripheral blood (in German). Zentralbl Gynakol 97: 307-310, 1975.

PEARSON MURPHY BE, STEINBERG SI, HU FY, ALLISON CM: Neuroactive ring A-reduced metabolites of progesterone in human plasma during pregnancy: elevated levels of 5 alpha-dihydroprogesterone in depressed patients during the latter half of pregnancy. J Clin Endocrinol Metab 86: 5981-5987, 2001.

PEPE GJ, ALBRECHT ED: Actions of placental and fetal adrenal steroid hormones in primate pregnancy. Endocr Rev 16: 608-648, 1995.

RUNNEBAUM B, RABE T: Regulation of human placental progesterone synthesis (in German). Geburtshilfe Frauenheilkd 43 (Suppl 1): 87-92, 1983.

RUNNEBAUM B, STOBER I, ZANDER J: Progesterone, 20 alpha-dihydroprogesterone and 20 betadihydroprogesterone in mother and child at birth. Acta Endocrinol (Copenh) 80: 569-576, 1975.

SAGEN N, ULSTEIN M, ROMSLO I, STOA KF: Plasma estriol, progesterone, cortisol, placental lactogen and alphafetoprotein in a pregnancy with an anencephalic fetus followed from the seventh week till term. Acta Obstet Gynecol Scand 58: 305-307, 1979.

SELCER KW, DIFRANCESCA HM, CHANDRA AB, LI PK: Immunohistochemical analysis of steroid sulfatase in human tissues. J Steroid Biochem Mol Biol 105: 115-123, 2007.

SHANKER YG, RAO AJ: Regulation of progesterone biosynthesis in the human placenta by estradiol 17 beta and progesterone. Biochem Mol Biol Int 43: 591-599, 1997.

SHAXTED EJ, HEYES VM, WALKER MP, MAYNARD PV: Umbilical-cord plasma progesterone in term infants delivered by caesarean section. Br J Obstet Gynaecol 89: 73-76, 1982.

SHEEHAN PM, RICE GE, MOSES EK, BRENNECKE SP: 5 Beta-dihydroprogesterone and steroid 5 beta-reductase decrease in association with human parturition at term. Mol Hum Reprod 11: 495-501, 2005.

SMITH R: Parturition. N Engl J Med 356: 271-283, 2007. 
SMITH R, MESIANO S, CHAN EC, BROWN S, JAFFE RB: Corticotropin-releasing hormone directly and preferentially stimulates dehydroepiandrosterone sulfate secretion by human fetal adrenal cortical cells. $J$ Clin Endocrinol Metab 83: 2916-2920, 1998.

SOLDIN OP, GUO T, WEIDERPASS E, TRACTENBERG RE, HILAKIVI-CLARKE L, SOLDIN SJ: Steroid hormone levels in pregnancy and 1 year postpartum using isotope dilution tandem mass spectrometry. Fertil Steril 84: 701-710, 2005.

SU EJ, CHENG YH, CHATTERTON RT, LIN ZH, YIN P, REIERSTAD S, INNES J, BULUN SE: Regulation of 17-beta hydroxysteroid dehydrogenase type 2 in human placental endothelial cells. Biol Reprod 77: 517-525, 2007.

ŠULCOVÁ J, HILL M, HAMPL R, STÁRKA L: Age and sex related differences in serum levels of unconjugated dehydroepiandrosterone and its sulphate in normal subjects. J Endocrinol 154: 57-62, 1997.

TORRICELLI M, IGNACCHITI E, GIOVANNELLI A, MEROLA A, SCARPETTI E, CALONACI G, PICCIOLINI E, FLORIO P, REIS FM, LINTON EA, PETRAGLIA F: Maternal plasma corticotrophin-releasing factor and urocortin levels in post-term pregnancies. Eur J Endocrinol 154: 281-285, 2006.

TROISI R, POTISCHMAN N, ROBERTS JM, HARGER G, MARKOVIC N, COLE B, LYKINS D, SIITERI P, HOOVER RN: Correlation of serum hormone concentrations in maternal and umbilical cord samples. Cancer Epidemiol Biomarkers Prev 12: 452-456, 2003.

TUCKEY RC: Progesterone synthesis by the human placenta. Placenta 26: 273-281, 2005.

WADDELL BJ, PEPE GJ, ALBRECHT ED: Progesterone and 20 alpha-hydroxypregn-4-en-3-one (20 alpha-OHP) in the pregnant baboon: selective placental secretion of 20 alpha-OHP into the fetal compartment. Biol Reprod 55: 854-859, 1996.

WARREN WB, PATRICK SL, GOLAND RS: Elevated maternal plasma corticotropin-releasing hormone levels in pregnancies complicated by preterm labor. Am J Obstet Gynecol 166: 1198-1204; discussion 1204-1207, 1992.

WESTCOTT KT, HIRST JJ, CIUREJ I, WALKER DW, WLODEK ME: Brain allopregnanolone in the fetal and postnatal rat in response to uteroplacental insufficiency. Neuroendocrinology 88: 287-292, 2008.

WINKEL CA, SNYDER JM, MACDONALD PC, SIMPSON ER: Regulation of cholesterol and progesterone synthesis in human placental cells in culture by serum lipoproteins. Endocrinology 106: 1054-1060, 1980.

YAWNO T, YAN EB, WALKER DW, HIRST JJ: Inhibition of neurosteroid synthesis increases asphyxia-induced brain injury in the late gestation fetal sheep. Neuroscience 146: 1726-1733, 2007. 